\title{
A PRODUÇÃO DO CONHECIMENTO EM SERVIÇO SOCIAL E ENVELHECIMENTO: TESES DE 1995 A 2019
}

Sergio Antonio Carlos - UFRGS - sacarlos@ufrgs.br

\section{RESUMO}

Introdução. A divulgação e a disseminação de estudos tanto na área do Serviço Social quanto na do envelhecimento tem crescido nos últimos anos no Brasil, incluindo teses e dissertações. Os assistentes sociais sempre estiveram à frente de ações relacionadas ao envelhecimento. Qual a produção dos mesmos sobre esta temática? Este estudo é parte de uma pesquisa maior sobre serviço social e envelhecimento no Brasil. Objetivo. Mapear a produção brasileira de teses e dissertações sobre serviço social e envelhecimento produzidas por assistentes sociais brasileiros(as). Métodos. A localização das teses foi feita através do Banco de Teses e Dissertações da CAPES e na Biblioteca Digital Brasileira de Teses e Dissertações do IBICT utilizando os termos: velhice, longevidade, terceira idade, idoso, gerontologia e envelhecimento. Foram excluídas as teses duplicadas, as que não abordavam o envelhecimento humano e as não produzidas por assistentes sociais. $\mathrm{O}$ corpus foi composto por 59 teses das 2.116 inicialmente localizadas. A análise foi descritiva a partir dos dados de identificação. Resultados. As teses foram defendidas entre 1995 e 2019 em 24 PPGs, sendo 67,80\% da área de SS da CAPES. Os estados com maior produção foram São Paulo (PUCSP 20,39\%) e Rio Grande do Sul (PUCRS 18,64\%). A maior produção foi nos últimos sete anos. A orientação foi realizada por 42 professores, dos quais 23 com graduação em Serviço Social. Conclusão. A produção está aumentando nos últimos anos. Há uma diversidade de áreas de conhecimento onde foram produzidas as teses bem como dos orientadores.

Palavras-chave: Envelhecimento; Assistentes sociais; bibliometria. 